\title{
Prevalence, Pattern, and Correlates of Polypharmacy among Iranian Type II Diabetic Patients: Results from Pars Cohort Study
}

\author{
Mahbobeh Azadi, MD, MPH ${ }^{1,2}$; Alireza Kamalipour, MD, MPH ${ }^{3}$; Hossein Molavi Vardanjani, MPH, PhD ${ }^{1,4}$; Hossein Poustchi, \\ MD $^{5}$; Erfan Taherifard, MD, MPH Student ${ }^{6}$; Mohammad Hossein Sharifi, PhD ${ }^{4}$; Alireza Salehi, PhD ${ }^{1}$; Zahra Mohammadi, MSc ${ }^{7}$ \\ ${ }^{1} \mathrm{MPH}$ Department, School of Medicine, Shiraz University of Medical Sciences, Shiraz, Iran \\ ${ }^{2}$ Pediatrics Resident of Shahid Beheshti Hospital, Kashan University of Medical Sciences, Esfahan, Iran \\ ${ }^{3}$ Hamilton Glaucoma Center, Shiley Eye Institute, Department of Ophthalmology, University of California, San Diego, CA, United \\ States \\ ${ }^{4}$ Research Center for Traditional Medicine and History of Medicine, Shiraz University of Medical Sciences, Shiraz, Iran \\ ${ }^{5}$ Digestive Disease Research Center, Digestive Disease Research Institute, Tehran University of Medical Science, Tehran, Iran \\ ${ }^{6}$ Student Research Committee, Shiraz University of Medical Sciences, Shiraz, Iran \\ ${ }^{7}$ Liver and Pancreatobiliary Disease Research Center, Digestive Disease Research Institute, Tehran University of Medical Science, \\ Tehran, Iran
}

\begin{abstract}
Background: Polypharmacy can negatively affect the life of type 2 diabetes (T2DM) patients. There is little evidence on the associated factors of, and patterns of polypharmacy among T2DM patients in developing regions. The aim of this study is to determine the population-based prevalence of polypharmacy, its associated factors, and pattern in southern Iran.

Methods: We used baseline data from the Pars Cohort Study (PCS). Age-standardized prevalence of polypharmacy and its 95\% confidence interval $(\mathrm{Cl})$ were estimated. Association of polypharmacy with demographic and socio-economic factors, anthropometric measures, serum biomarkers, physical activity, cigarette and tobacco smoking, and multimorbidity was assessed by applying multivariable Poisson modeling. Prevalence ratio (PR) and its $\mathrm{Cl}$ were estimated. The Anatomical Therapeutic Chemical (ATC) classification system was used for drug classification.

Results: Totally, 874 previously diagnosed T2DM patients with a mean age of $56.3 \pm 9.2$ participated in the study. The estimated agestandardized prevalence for men and women was $17.2 \%$ (Cl: $12.0-22.0)$ and $34.1 \%$ (Cl: $33.2-39.4)$, respectively. The prevalence of hypertension, hyperlipidemia and cardiovascular disorders among the study population was $39 \%, 58 \%$ and $20 \%$, respectively. Having more than four comorbidities ( $\mathrm{PR}, 3.90 ; \mathrm{Cl}, 2.39-6.34)$, central obesity (PR, 2.66; $\mathrm{Cl}, 1.03-6.84)$, and female gender (PR, $1.49 ; \mathrm{Cl}, 1.14-1.97$ ) were associated with polypharmacy. Also, $56.0 \%$ of patients and $23.0 \%$ of elder patients ( $>59$ years old) reported using anti-diabetic agents.

Conclusion: Polypharmacy was low among T2DM patients. More than $75 \%$ of the elder population were not on anti-diabetic medications. Polypharmacy was higher among patients with multiple comorbidities, central obesity, lower physical activity, lower socio-economic status, younger age at diagnosis, and longer duration of T2DM.

Keywords: Diabetes mellitus type 2, Epidemiology, Iran, Polypharmacy

Cite this article as: Azadi M, Kamalipour A, Molavi Vardanjani H, Poustchi H, Taherifard E, Sharifi MH, et al. Prevalence, pattern, and correlates of polypharmacy among iranian type ii diabetic patients: results from pars cohort study. Arch Iran Med. 2021;24(9):657-664. doi: 10.34172/aim.2021.94
\end{abstract}

Received: August 12, 2020, Accepted: November 4, 2020, ePublished: September 1, 2021

\section{Introduction}

Type 2 diabetes (T2DM) is one of the leading causes of the global burden of diseases. The evidence shows that 114 million (11\%) adults currently live with T2DM, which is anticipated to rise to 120 million by $2045 .{ }^{1}$ A high proportion of these patients may suffer from microvascular and macrovascular complications, and also from comorbidities such as coronary artery disease, hypertension, dyslipidemia, chronic kidney disease, and depression. Therefore, they have to use many medications to manage their glycemic indices, and to prevent or control the complications of their diabetes, or other comorbidities. ${ }^{2}$ This leads to a situation called polypharmacy, using five or more drugs, which is highly common, from $57 \%$ to $84 \%$, among T2DM patients in the developed countries. ${ }^{3,4}$

Polypharmacy affects the quality of life and well-being of patients. ${ }^{5,6}$ It is an indicator of higher mortality. Polypharmacy is also a risk factor for adverse outcomes, such as hospitalizations, drug interactions, prescription 
cascade, adverse drug reactions, medical dosing errors, and low adherence to medication, which will end in serious adverse clinical outcomes. ${ }^{8-10}$

Although there is a huge body of evidence on the polypharmacy in the developed countries, we know less about this issue in the developing and less developed regions. ${ }^{11,12}$ Lack of evidence from developing countries occurs as a result of inadequate disease management in most of these areas - a condition that will lead to more complications, more comorbidities, and consequently higher prevalence of polypharmacy. In addition, less evidence is available about the prevalence of polypharmacy and its associated factors among T2DM patients even in the developed regions. ${ }^{2}$

Therefore, there is a need to investigate the prevalence, pattern and associated factors of polypharmacy among T2DM patients, especially in the developing and less developed regions. Such evidence will improve the management of T2DM and its complications. ${ }^{13}$ The resultant evidence may be used to improve drug adherence in T2DM patients. Furthermore, this may help clinicians to appropriately deal with the challenging task of finding a balance between the advantages and disadvantages of drug therapy. ${ }^{14}$

The aim of this study was to investigate the populationbased prevalence of polypharmacy, its pattern and associated factors among T2DM patients in southern Iran.

\section{Materials and Methods Study Design, Setting and Participants}

This is a cross-sectional study which was performed to investigate the population-based prevalence of polypharmacy, its pattern and associated factors among T2DM patients in southern Iran. We used baseline data from the Pars Cohort Study (PCS). Details of PCS are described elsewhere. ${ }^{15}$ In brief, PCS is an ongoing population-based prospective study started in 2012 to investigate the epidemiology of risk factors of noncommunicable diseases in a semi-urban area, i.e. Valashahr, located in southern Iran. A total of 9,264 residents aged 40-75 were invited and agreed to take part in PCS.

As this study is based on the PCS baseline data, no sample size calculation was done. Almost all of T2DM patients participated in the PCS including newly diagnosed patients, and patients with a previous diagnosis of T2DM were eligible for this study. Patients without data on their drug use $(n=2)$ were excluded from this study.

\section{Data Collection and Variable Definition}

Data was collected by face-to-face interviews, performing physical examination, measuring anthropometric indices, and obtaining biomedical samples by trained personnel using standardized and calibrated equipment. Details are published elsewhere. ${ }^{15,16}$

Polypharmacy was defined as concurrent use of five or more drugs. ${ }^{5}$ Drug use data was collected by asking participants to bring their bag of medications they were using to the PCS center. The drugs inside the bag were then listed by a trained nurse. To check the current medication use, the participants were asked if they were currently using all the medications inside their medication bag. The drugs that each participant was currently using were listed regarding to the participant's medication list. We counted the number of drugs for each participant, and then categorized participants in two groups of having polypharmacy (using five or more drugs), and not having polypharmacy (using fewer than five drugs).

Based on our literature review, a theoretical conceptual model was designed. Based on that model, potential covariates of polypharmacy were retrieved from the PCS database, and entered in the analyses. These potential covariates and their definition were as follows: age $(<50$, $50-59$, and $\geq 60$ ), gender, education (literate, illiterate), marital status (married, widowed/divorced), ethnicity (Persian/others), socio-economic status (low, low-middle, middle-high, high), physical activity (low, moderate, high), tobacco smoking (smoker, non-smoker), central obesity (with central obesity, without central obesity), fasting blood sugar (90-130, 130-160, 160-190, and >190 $\mathrm{mg} / \mathrm{dL}$ ), low density lipoprotein-cholesterol (LDL >200 $\mathrm{mg} / \mathrm{dL}, \mathrm{LDL} \leq 200)$, high density lipoprotein- cholesterol (HDL $<60 \mathrm{mg} / \mathrm{dL}, \mathrm{HDL} \geq 60)$, total cholesterol $(<200$ $\mathrm{mg} / \mathrm{dL}, 200-239$, and $\geq 240)$, triglyceride $(\leq 150 \mathrm{mg} / \mathrm{dL}$, $150-199$, and $\geq 200)$, body mass index $(<25,25-29.9$, and $\geq 30$ ), comorbidity $(<3,3-4$, and $>4)$, time from diagnosis of T2DM (within 2 years, 2 to 9 years, and 10 and years more), and age at diagnosis of T2DM $(<40,40-49$, and $\geq 50$ ).

To measure the relative ranking of participants' socioeconomic status, we asked them to list their assets based on a standardized form for Iran. In this study, we performed the asset analysis applying multiple correspondence analysis and estimated a latent factor, and then categorized the study participants into four groups based on quartiles of the estimated latent factor. Physical activity data were converted to Metabolic Equivalent of Task scores and the participants were then categorized into three groups including high (at least 3000 METminutes/week), moderate (at least 600 MET-minutes/ week), and low (less than $600 \mathrm{MET}$-minutes/week).

Height was measured to the nearest centimeter while the subjects were barefoot. Weight was measured to the nearest $0.1 \mathrm{~kg}$ using a scale while the subjects wore light clothes. Then, body mass index (BMI) was calculated and categorized based on the World Health Organization (WHO) protocol. ${ }^{17}$ To measure central obesity, we used data on two measures including waist circumference (WC), and waist-hip ratio (WHR). WC and WHR were calculated and categorized based on the WHO recommendations. ${ }^{18,19}$

To determine the status of comorbidities, the participants were asked about a list of diseases, "whether 
or not your doctor or health care provider has ever diagnosed each of these diseases for you". Then, we calculated a score for each participant by counting her/ his chronic comorbidities. The participants were then divided into three groups, including only diabetes, three or four comorbidities, and more than four comorbidities.

Considering the date of diagnosis of T2DM and the date of the interview, we measured the duration of T2DM (in years) for each participant.

Patterns of drug use among T2DM patients were investigated by reporting the percentage of using different drug classes among participants. Drug classification was done based on the Anatomical Therapeutic Chemical (ATC) classification system $\left(1^{\text {st }}\right.$ level $) .{ }^{20}$

\section{Statistical Analysis}

Data was cleaned and checked for internal and external inconsistencies, and also the presence of outlier and missing values by applying appropriate techniques. ${ }^{21}$

Frequencies and relative frequencies were calculated for categorical variables. Mean and standard deviation (SD) were used to describe quantitative variables. Prevalence and its 95\% confidence interval (CI) were estimated. Agestandardized prevalence of polypharmacy and its CI was estimated considering the world standard population distribution in 2000-2025. Chi-square and Mann-Whitney $\mathrm{U}$ tests were applied for univariate analyses, and statistical variable selection. Considering the cross-sectional nature of the study data and to prevent overestimation of prevalence ratios, modified Poisson regression (Poisson regression with robust standard errors) modeling was applied to determine the independent associated factors of prevalence of polypharmacy. To do this, variables with a univariate $P$ value of less than 0.3 were included in the multivariable modeling as potential independent variables. The final model was fitted using a backward elimination (BL) technique. A 0.2 alpha level was presumed as the stopping criterion for BL. Prevalence ratio and its $95 \%$ CI were estimated. A $P$ value of less than 0.05 was considered as statistically significant.

\section{Results}

Data from 874 patients including 273 (31.2\%) men and $601(68.8 \%)$ women was analyzed. The mean age of the study participants was $56.3 \pm 9.2$ years. The crude prevalence of polypharmacy was $32.0 \%$ (CI: 28.0-36.0): 17.9\% (CI: $13.0-23.0$ ) for men and 38.0\% (CI: 33.0-43.0) for women. Gender and age-standardized prevalence was 29.0\% (CI: 25.0-32.0). Age-standardized prevalence was 17.2\% (CI: 12.0-22.0) for men and 34.0\% (CI: 29.0-39.0) for women. Mean duration of T2DM was significantly different between patients with (4.87 with a $95 \%$ CI of 4.47 to 5.27 years) and without (6.28 with a 95\% CI of 5.61 to 6.94 years) polypharmacy (Figure 1).

The highest (46\%) and lowest (10\%) prevalence of polypharmacy was estimated for those who suffered from more than 4 comorbidities and those without
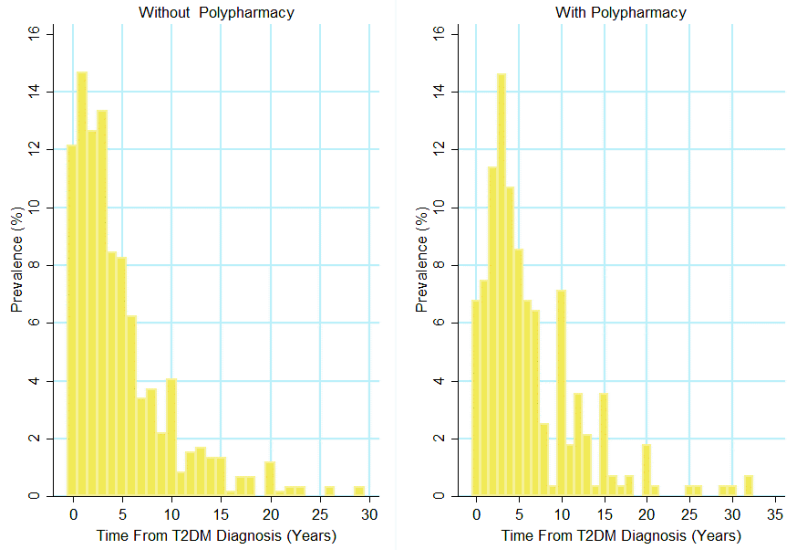

Figure 1. Duration of T2DM for Patients with and without Polypharmacy.

one or two comorbidities. Among the comorbidities in these participants, the prevalence of hyperlipidemia, hypertension and cardiovascular disorders was 58\%, 39\% and $20 \%$, respectively. The prevalence of polypharmacy was at $39 \%$ in patients with the lowest level of physical activity (Table 1).

Suffering from more than 4 comorbidities increased the prevalence of polypharmacy by $3.90(2.39,6.34)$ times. The prevalence of polypharmacy in the highest socioeconomic status (SES) level was meaningfully higher than that in the lowest SES level (PR, 1.31; CI, 0.99, 1.74; Table 2).

Among study participants, $44 \%$ of women, $43 \%$ of men, and $77 \%$ of elder patients did not take anti-diabetic medications. About half (50\%) of T2DM patients used drugs of the cardiovascular class (Table 3).

\section{Discussion}

In this population-based study, polypharmacy was observed in one out of three diabetic patients. The prevalence of polypharmacy among females was twice as that of males. More comorbidities, central obesity, female gender, higher SES, lower age at T2DM diagnosis, longer duration of T2DM, physical inactivity, and Persian ethnicity were associated factors of higher prevalence of polypharmacy among T2DM patients. We showed that more than half of study participants and most of the elder patients did not use conventional anti-diabetic drugs.

The prevalence of polypharmacy as reported in this study was much lower than those reported from studies in other countries. ${ }^{1,2,22}$ In a study conducted at a tertiary care center in China, it was revealed that $72.2 \%$ of patients with DM had polypharmacy. ${ }^{1}$ This lower rate may be due to earlier diagnosis of DM or shorter duration of T2DM in our study population. When patients with impaired glucose tolerance are detected at an earlier age, these individuals forming the diabetic population are less likely to have the comorbidities found among the elderly. Furthermore, when DM control and management starts from an earlier age, the complications of DM are less likely to develop, and therefore, the need for extra medications declines as well. ${ }^{23}$ On the other hand, our lower prevalence 
Table 1. Characteristics of T2DM Patients Enrolled in the Pars Cohort Study

\begin{tabular}{|c|c|c|c|c|}
\hline \multicolumn{2}{|c|}{ Characteristics } & \multirow{2}{*}{$\begin{array}{c}\text { Total, n (\% of Total) } \\
\mathbf{8 7 4 ( \mathbf { 1 0 0 } )} \\
238(27)\end{array}$} & \multirow{2}{*}{$\begin{array}{l}\text { Polypharmacy, n (\% in Row) } \\
\text { 281 (32) } \\
60(25)\end{array}$} & \multirow[t]{2}{*}{$P$ value } \\
\hline \multirow{3}{*}{ Age (y) } & $40-49$ & & & \\
\hline & $50-59$ & $308(35)$ & $99(32)$ & \multirow[t]{2}{*}{0.011} \\
\hline & $60+$ & $328(38)$ & $122(37)$ & \\
\hline \multirow{3}{*}{ Age at diagnosis of T2DM (y) } & Less than 40 & $91(10)$ & $32(35)$ & \multirow{3}{*}{0.219} \\
\hline & $40-49$ & $306(35)$ & $87(28)$ & \\
\hline & 50 and above & $477(56)$ & $162(34)$ & \\
\hline \multirow{3}{*}{ T2DM duration (y) } & Less than 2 & $199(23)$ & $40(20)$ & \multirow{3}{*}{$<0.001$} \\
\hline & $3-9$ & $517(59)$ & $172(34)$ & \\
\hline & 10 and above & $158(18)$ & $69(44)$ & \\
\hline \multirow{3}{*}{ Cholesterol (mg/dL) } & Less than 200 & $479(55)$ & $165(34)$ & \multirow{3}{*}{0.094} \\
\hline & 200-239 & $244(28)$ & $65(27)$ & \\
\hline & $240+$ & $151(17)$ & $51(34)$ & \\
\hline \multirow{3}{*}{ Triglyceride (mg/dL) } & Less than 150 & $383(44)$ & $111(29)$ & \multirow{3}{*}{0.041} \\
\hline & 150-199 & $179(20)$ & $53(30)$ & \\
\hline & $200+$ & $312(36)$ & $117(38)$ & \\
\hline \multirow{3}{*}{ Physical activity } & Low & $381(44)$ & $148(39)$ & \multirow{3}{*}{$<0.001$} \\
\hline & Moderate & $293(34)$ & $86(29)$ & \\
\hline & High & $200(23)$ & $47(24)$ & \\
\hline \multirow{3}{*}{ BMI $\left(\mathrm{kg} / \mathrm{m}^{2}\right)$} & Normal weight & 249 (29) & $65(26)$ & \multirow{3}{*}{0.022} \\
\hline & Over weight & $402(46)$ & $133(33)$ & \\
\hline & Obese & $216(25)$ & $82(38)$ & \\
\hline \multirow{2}{*}{ Ethnicity } & Non-Persian & $313(36)$ & $72(23)$ & \multirow{2}{*}{$<0.001$} \\
\hline & Persian & $561(64)$ & $209(37)$ & \\
\hline \multirow{4}{*}{ Socio-Economic status } & Low & $210(24)$ & $54(26)$ & \multirow{4}{*}{0.069} \\
\hline & Low-Middle & $228(26)$ & $84(37)$ & \\
\hline & Middle-High & $210(24)$ & $73(35)$ & \\
\hline & High & $226(26)$ & $70(31)$ & \\
\hline \multirow{3}{*}{ Comorbidity } & One or two & $148(17)$ & $15(10)$ & \\
\hline & Three or four & $316(36)$ & $76(24)$ & $<0.001$ \\
\hline & More than 4 & $410(47)$ & $190(46)$ & \\
\hline & Less than 90 & $59(7)$ & $12(4)$ & \\
\hline & 90-130 mg/dL & $349(40)$ & $93(33)$ & \\
\hline Fasting blood glucose & $131-160 \mathrm{mg} / \mathrm{dL}$ & $118(14)$ & $46(16)$ & 0.003 \\
\hline & $161-190 \mathrm{mg} / \mathrm{dL}$ & $88(10)$ & $36(13)$ & \\
\hline & $>190$ mg/dL & $260(30)$ & $94(34)$ & \\
\hline Marita ctatuc & Not married & $124(14)$ & $47(38)$ & 0141 \\
\hline Marmal status & Married & 749 (86) & $234(31)$ & 0.141 \\
\hline Gender & Male & $273(31)$ & $49(18)$ & $<0001$ \\
\hline & Female & $601(69)$ & $232(38)$ & \\
\hline Eduration & Literate & 343 (39) & $99(29)$ & 0094 \\
\hline Eaucation & Illiterate & $531(61)$ & $182(34)$ & 0.094 \\
\hline Tobacco cmoling & Smoker & $439(50)$ & $140(32)$ & 0870 \\
\hline I0Dacco smoking & Non-smoker & $432(50)$ & $140(32)$ & $0.8 / 0$ \\
\hline Central obecity & Yes & $514(59)$ & $202(39)$ & $<0001$ \\
\hline Central obesity & No & $360(41)$ & $79(22)$ & $<0.001$ \\
\hline low-density lipoprotein & $>200$ & $392(44)$ & $150(38)$ & $<0.001$ \\
\hline high-density lipoprotein & $<60$ & $547(63)$ & $165(30)$ & 0.104 \\
\hline
\end{tabular}

of polypharmacy may be explained by lack of appropriate medical prescription or healthcare utilization by our study population, especially in males..$^{24}$ Another explanation for this finding may arise as a result of the population-based nature of this study compared to other hospital-based studies. In addition, Iran's primary healthcare system in rural areas is highly effective, and therefore, this lower prevalence may be because of the adequacy of T2DM 
Table 2. Associated Factors of Prevalence of Polypharmacy in T2D Patients

\begin{tabular}{|c|c|c|c|c|c|}
\hline Factors & & n (\%) & $\begin{array}{c}\text { Adjusted Prevalence } \\
\text { Ratio }(95 \% \mathrm{Cl}) \\
\end{array}$ & $P$ value* & $\begin{array}{c}\text { Crude Prevalence } \\
\text { Ratio }(95 \% \mathrm{Cl})\end{array}$ \\
\hline \multirow{2}{*}{$\begin{array}{l}\text { Comorbidity (Ref.: T2DM } \\
\text { only) }\end{array}$} & 3 or 4 comorbidities & $316(36)$ & $2.07(1.26,3.42)$ & 0.004 & $2.37(1.41,3.98)$ \\
\hline & More than 4 & $410(47)$ & $3.90(2.39,6.34)$ & $<0.001$ & $4.57(2.79,7.47)$ \\
\hline \multicolumn{2}{|l|}{ Central Obesity } & $817(94)$ & $2.66(1.03,6.84)$ & 0.041 & $4.22(1.64,10.86)$ \\
\hline \multicolumn{2}{|l|}{ Female gender } & $273(31)$ & $1.49(1.14,1.97)$ & 0.004 & $2.15(1.63,2.82)$ \\
\hline \multirow{4}{*}{$\begin{array}{l}\text { Level of FBS (Ref.: Less than } \\
\text { 90) }\end{array}$} & $90-130 \mathrm{mg} / \mathrm{dL}$ & $349(40)$ & $1.31(0.81,2.12)$ & 0.269 & $1.31(0.77,2.24)$ \\
\hline & $131-160 \mathrm{mg} / \mathrm{dL}$ & $118(14)$ & $1.88(1.15,3.08)$ & 0.012 & $1.92(1.10,3.33)$ \\
\hline & $161-190 \mathrm{mg} / \mathrm{dL}$ & $88(10)$ & $2.10(1.27,3.46)$ & 0.004 & $2.01(1.14,3.54)$ \\
\hline & $>190 \mathrm{mg} / \mathrm{dL}$ & $260(30)$ & $1.57(0.98,2.53)$ & 0.059 & $1.78(1.05,3.02)$ \\
\hline \multicolumn{2}{|c|}{ Persian Ethnicity (Ref.: non-Persian) } & $561(64)$ & $1.38(1.12,1.71)$ & 0.002 & $1.61(1.28,2.03)$ \\
\hline \multirow{3}{*}{ SES (Ref.: Low) } & Low-middle & $228(26)$ & $1.36(1.04,1.78)$ & 0.022 & $1.43(1.07,1.90)$ \\
\hline & Middle-High & $210(24)$ & $1.37(1.04,1.80)$ & 0.021 & $1.35(1.00,1.86)$ \\
\hline & High & $226(26)$ & $1.31(0.99,1.74)$ & 0.052 & $1.20(0.89,1.62)$ \\
\hline \multicolumn{2}{|c|}{ Abnormal LDL (Ref.: less than 100) } & $392(45)$ & $1.34(1.13,1.60)$ & 0.001 & $1.40(1.16,1.70)$ \\
\hline \multirow[b]{2}{*}{ Age } & Current age (10 years) & $874(100)$ & $1.32(1.14,1.53)$ & $<0.001$ & $1.12(1.01,1.23)$ \\
\hline & $\begin{array}{l}\text { Age at DM diagnosis ( } 5 \\
\text { years) }\end{array}$ & $874(100)$ & $0.89(0.83,0.95)$ & 0.001 & $1.00(0.95,1.05)$ \\
\hline \multirow{2}{*}{ Physical activity (Ref.: low) } & Moderate & $293(34)$ & $0.79(0.65,0.96)$ & 0.021 & $0.75(0.60,0.93)$ \\
\hline & High & $200(23)$ & $0.86(0.65,1.13)$ & 0.293 & $0.60(0.45,0.80)$ \\
\hline \multirow{2}{*}{$\begin{array}{l}\text { Disease duration (Ref. } \\
\text { within } 2 \text { years) }\end{array}$} & $3-9$ years & $517(59)$ & $1.60(1.17,2.18)$ & 0.003 & $1.67(1.21,2.30)$ \\
\hline & 10 and more years & $158(18)$ & $2.16(1.49,3.13)$ & $<0.001$ & $2.17(1.56,3.02)$ \\
\hline
\end{tabular}

${ }^{*} P$ values are based on multivariable modeling.

Table 3. ATC Classification of Drugs Used by T2D Patients

\begin{tabular}{lcccc}
\hline Drug Class & Total & Men & Women & >59 Years Old \\
$\mathbf{n}(\mathbf{\%})$ & $\mathbf{n}(\mathbf{\%})$ & $157(57)$ & $340(56)$ & $39(23)$ \\
\hline Anti-diabetic agent & $497(56)$ & $112(41)$ & $318(52)$ & $49(29)$ \\
Cardiovascular system & $440(50)$ & $69(25)$ & $280(46)$ & $34(20)$ \\
Genitourinary system and sex hormones & $349(39)$ & $58(21)$ & $224(37)$ & $54(32)$ \\
Blood and blood forming agents & $282(32)$ & $51(18)$ & $163(27)$ & $45(26)$ \\
Alimentary tract and metabolism & $214(24)$ & $47(17)$ & $83(13)$ & $22(13)$ \\
Nervous systems & $130(14)$ & $48(17)$ & $73(12)$ & $29(17)$ \\
Musculoskeletal system & $121(13)$ & $12(4)$ & $69(11)$ & $18(10)$ \\
\hline Other drugs & $81(9)$ & & &
\end{tabular}

management among the study population. Moreover, this study is cross-sectional, and there is a possibility of incidence-prevalence bias. Another probable reason may be that those T2DM patients with polypharmacy died earlier and had no chance to participate in this study. Further studies are needed to investigate the quality of T2DM screening and management in this region.

Having more comorbidities was associated with a higher prevalence of polypharmacy. Development of polypharmacy in patients with multimorbidity often results from targeting each disease with its specific medications by different specialists. Different doctors prescribing different medications for one patient leads to adverse drug reactions and prescription cascade, mainly from drug-drug interactions. ${ }^{22,25}$ To lower the extent of this complication, it is suggested that family physicians review each patient's drug history and consult with the patient's specialists whether the medications could be substituted with another one in the condition of drug-drug interactions. Furthermore, in some patients, instead of taking multiple drugs, polypills can be considered. ${ }^{26}$ Recently, guidelines for DM have been designed to account for likely comorbidities by suggesting different medications in diabetic patients with these comorbidities. ${ }^{20}$ On the other hand, there is a probable reverse causal relationship between polypharmacy and multi-morbidity. Some drugs could induce some diseases, and accordingly, polypharmacy could result in a higher chance of having more than one disease. This should be investigated in further prospective studies.

Female gender was positively associated with the prevalence of polypharmacy. Concordant with this 
finding, previous studies reported that among patients with diabetes, polypharmacy is seen more in women than men. ${ }^{2,4}$ Women are typically more concerned about their health status and have more health-seeking behaviors in comparison to men. Therefore, they tend to take more drugs. Besides, health seeking behavior in the context of lack of rigid guidelines on prescription limit and high access to medications in Iran, easily leads to taking more drugs and self-medication, giving rise to appearance of prescription cascade. ${ }^{24,27}$ These behaviors may be responsible for the higher prevalence of polypharmacy in women.

Central obesity is another factor associated with the higher prevalence of polypharmacy. This relationship between central obesity and polypharmacy is reported in other studies. ${ }^{28}$ Central obesity is documented to be a risk factor in the pathogenesis of many diseases such as diabetes, cardiovascular diseases, musculoskeletal diseases and other diseases. ${ }^{29,30}$ Therefore, in an individual with diabetes, presence of this risk factor leads to increased possibility of other comorbidities and thereafter, taking multiple medications, i.e. polypharmacy.

Another finding of this study was a non-significant but meaningful difference between the lowest and highest SES levels. We think it may be a result of the fact that the lowest and highest SES levels lead to lower healthcare utilization and better health status, respectively. ${ }^{31,32}$ Such findings have been also reported by others. ${ }^{33}$ However, participants with higher SES may use more supplementary drugs such as multi-vitamins. This could results in a higher number of drugs that are consumed by participants from higher SES subpopulations.

Inconsistent with a previous report, ${ }^{34}$ our study revealed that physical activity has a protective role against polypharmacy. The way that higher physical activity could result in a lower prevalence of polypharmacy may be the more appropriate health behaviors in patients with higher physical activity compared with those who are less active physically. These findings emphasize the importance of taking daily exercises into account in diabetes care and management. ${ }^{35}$

One of the most surprising findings of our study was that almost half of our study population were not on conventional anti-diabetic drugs. Similar results have been reported from Japan and other regions. ${ }^{36,37}$ The findings of another report from Iran are inconsistent with ours. ${ }^{38}$ This disagreement maybe a result of the population-based nature of our study compared with the hospital-based nature of the mentioned report. This population is divided into two subgroups: individuals who have recently become aware of their high blood sugar and diabetic state and therefore, have not sought medication yet, and those individuals who were diagnosed with T2DM previously, before enrollment in the PCS and were on traditional medications or non-medical methods for lowering T2DM sequels such as lifestyle changes. ${ }^{39}$ In both groups, it is important to discuss the short-term and long-term complications of persistent high levels of blood glucose with the patients and recommend them to have good glycemic control. The proportion of diabetic patients who are not on conventional anti-diabetic drugs reaches almost three-fourths in the elderly. It seems that diabetes care in the elderly population is inadequate, and further studies are needed on the quality of diabetes care in this population and similar populations.

Our study had some limitations. In patients who were not on anti-diabetic agents, the means they apply to lower their blood sugar was not questioned. Another limitation of this study was the cross-sectional nature of our data. Accordingly, we were not able to know the temporality of independent and dependent variables of the study. In addition, we had no data available on $\mathrm{HbAlc}$, as the most reliable measure of T2DM control. Besides these limitations, our study had some strengths. In this study, we did not rely on the patients' memory and we asked them to bring their medications with themselves. Moreover, this population-based work was the first study conducted in Iran among patients with T2DM assessing polypharmacy.

In conclusion, polypharmacy was not high in the diabetic population of Iran and was significantly lower than developed countries. T2DM patients with several comorbidities, central obesity, lower physical activity, younger age at diagnosis of T2DM, longer duration of T2DM, and those from deprived populations have a higher prevalence of polypharmacy. Almost half of the study population and more than $75 \%$ of the elderly population were not on conventional anti-diabetic medications. In this regard, more attention needs to be paid to the subject of polypharmacy and adherence to medication by researchers, clinicians and healthcare providers.

\section{Authors' Contribution}

MA: Initial drafting. HMV: Study conceptualization and design, statistical analysis, revising the manuscript. ARK: Statistical analysis, results interpretation and manuscript revision. ET: Initial drafting. MHS: Results interpretation and initial drafting. HP: Study design and execution of the PCS data collection. ZM: Interpretation of study results. AS: Interpretation of study results. All authors read and approved the final manuscript.

\section{Conflict of Interest Disclosures}

The authors declared that they had no competing interests.

\section{Ethical Statement}

The PCS protocol was approved by the Ethics Committees of Tehran and Shiraz University of Medical Sciences. Written informed consent was obtained from all participants.

\section{Acknowledgments}

We sincerely thank Professor Reza Malekzadeh for founding the Pars Cohort Study (PCS).

\section{References}


1. Li J, Chattopadhyay K, Xu M, Chen Y, Hu F, Wang X, et al. Prevalence and predictors of polypharmacy prescription among type 2 diabetes patients at a tertiary care department in Ningbo, China: a retrospective database study. PLoS One. 2019;14(7):e0220047. doi: 10.1371/journal.pone.0220047.

2. Alwhaibi M, Balkhi B, Alhawassi TM, Alkofide H, Alduhaim $\mathrm{N}$, Alabdulali R, et al. Polypharmacy among patients with diabetes: a cross-sectional retrospective study in a tertiary hospital in Saudi Arabia. BMJ Open. 2018;8(5):e020852. doi: 10.1136/bmjopen-2017-020852.

3. Grant RW, Devita NG, Singer DE, Meigs JB. Polypharmacy and medication adherence in patients with type 2 diabetes. Diabetes Care. 2003;26(5):1408-12. doi: 10.2337/ diacare.26.5.1408.

4. Pahuja G, Kumar P, Ghildiyal S, Nesari T. Polypharmacy in diabetes: a boon or a bane. Indian J Health Sci Biomed Res. 2020;13(1):11-5. doi: 10.4103/kleuhsj.kleuhsj_175_19.

5. Masnoon N, Shakib S, Kalisch-Ellett L, Caughey GE. What is polypharmacy? a systematic review of definitions. BMC Geriatr. 2017;17(1):230. doi: 10.1186/s12877-017-0621-2.

6. Montiel-Luque A, Núñez-Montenegro AJ, MartínAurioles E, Canca-Sánchez JC, Toro-Toro MC, GonzálezCorrea JA. Medication-related factors associated with health-related quality of life in patients older than 65 years with polypharmacy. PLoS One. 2017;12(2):e0171320. doi: 10.1371/journal.pone.0171320.

7. Jyrkkä J, Enlund H, Korhonen MJ, Sulkava R, Hartikainen S. Polypharmacy status as an indicator of mortality in an elderly population. Drugs Aging. 2009;26(12):1039-48. doi: 10.2165/11319530-000000000-00000.

8. Nguyen JK, Fouts MM, Kotabe SE, Lo E. Polypharmacy as a risk factor for adverse drug reactions in geriatric nursing home residents. Am J Geriatr Pharmacother. 2006;4(1):3641. doi: 10.1016/j.amjopharm.2006.03.002.

9. Sorensen L, Stokes JA, Purdie DM, Woodward M, Roberts MS. Medication management at home: medication-related risk factors associated with poor health outcomes. Age Ageing. 2005;34(6):626-32. doi: 10.1093/ageing/afi202.

10. Zelko E, Klemenc-Ketis Z, Tusek-Bunc K. Medication adherence in elderly with polypharmacy living at home: a systematic review of existing studies. Mater Sociomed. 2016;28(2):129-32. doi: 10.5455/msm.2016.28.129-132.

11. Hovstadius B, Petersson G. Factors leading to excessive polypharmacy. Clin Geriatr Med. 2012;28(2):159-72. doi: 10.1016/j.cger.2012.01.001.

12. Rieckert A, Trampisch US, Klaaßen-Mielke R, Drewelow E, Esmail A, Johansson T, et al. Polypharmacy in older patients with chronic diseases: a cross-sectional analysis of factors associated with excessive polypharmacy. BMC Fam Pract. 2018;19(1):113. doi: 10.1186/s12875-018-0795-5.

13. Johansson T, Abuzahra ME, Keller S, Mann E, Faller $\mathrm{B}$, Sommerauer $\mathrm{C}$, et al. Impact of strategies to reduce polypharmacy on clinically relevant endpoints: a systematic review and meta-analysis. Br J Clin Pharmacol. 2016;82(2):532-48. doi: 10.1111/bcp.12959.

14. Scott IA, Hilmer SN, Reeve E, Potter K, Le Couteur D, Rigby $\mathrm{D}$, et al. Reducing inappropriate polypharmacy: the process of deprescribing. JAMA Intern Med. 2015;175(5):827-34. doi: 10.1001/jamainternmed.2015.0324.

15. Gandomkar A, Poustchi H, Moini M, Moghadami M, Imanieh H, Fattahi MR, et al. Pars cohort study of noncommunicable diseases in Iran: protocol and preliminary results. Int J Public Health. 2017;62(3):397-406. doi: 10.1007/s00038-016-0848-2.

16. Akbarzadeh A, Salehi A, Molavi Vardanjani H, Poustchi H, Gandomkar A, Fattahi MR, et al. Epidemiology of adult diabetes mellitus and its correlates in pars cohort study in Southern Iran. Arch Iran Med. 2019;22(11):633-9.

17. Body mass index - BMI Copenhagen, Denmark: World Health Organization (WHO Regional Office for Europe). Available from: http://www.euro.who.int/en/healthtopics/disease-prevention/nutrition/a-healthy-lifestyle/ body-mass-index-bmi.

18. Waist circumference and waist-hip ratio: World Health Organization. World Health Organization; 2008. Available from: https://www.who.int/publications-detailredirect/9789241501491.

19. World Health Organization (WHO). Waist Circumference and Waist-Hip Ratio: Report of a WHO Expert Consultation, Geneva, 8-11 December 2008. WHO; 2011.

20. Rydén L, Standl E, Bartnik M, Van den Berghe G, Betteridge J, de Boer MJ, et al. Guidelines on diabetes, pre-diabetes, and cardiovascular diseases: executive summary. The Task Force on Diabetes and Cardiovascular Diseases of the European Society of Cardiology (ESC) and of the European Association for the Study of Diabetes (EASD). Eur Heart J. 2007;28(1):88-136. doi: 10.1093/eurheartj/ehl260.

21. Molavi Vardajani H, Haghdoost AA, Shahravan A, Rad M. Cleansing and preparation of data for statistical analysis: a step necessary in oral health sciences research. J Oral Health Oral Epidemiol. 2016;5(4):171-85.

22. Noale M, Veronese N, Cavallo Perin P, Pilotto A, Tiengo A, Crepaldi G, et al. Polypharmacy in elderly patients with type 2 diabetes receiving oral antidiabetic treatment. Acta Diabetol. 2016;53(2):323-30. doi: 10.1007/s00592-0150790-4.

23. Laiteerapong N, Ham SA, Gao Y, Moffet HH, Liu JY, Huang ES, et al. The legacy effect in type 2 diabetes: impact of early glycemic control on future complications (the Diabetes \& Aging Study). Diabetes Care. 2019;42(3):41626. doi: $10.2337 / \mathrm{dc} 17-1144$.

24. Khajeh A, Molavi Vardanjani H, Salehi A, Rahmani N, Delavari S. Healthcare-seeking behavior and its relating factors in South of Iran. J Educ Health Promot. 2019;8:183. doi: 10.4103/jehp.jehp_93_19.

25. Al-Musawe L, Martins AP, Raposo JF, Torre C. The association between polypharmacy and adverse health consequences in elderly type 2 diabetes mellitus patients; a systematic review and meta-analysis. Diabetes Res Clin Pract. 2019;155:107804. doi: 10.1016/j.diabres.2019.107804.

26. Roshandel G, Khoshnia M, Poustchi H, Hemming K, Kamangar F, Gharavi A, et al. Effectiveness of polypill for primary and secondary prevention of cardiovascular diseases (PolyIran): a pragmatic, cluster-randomised 
trial. Lancet. 2019;394(10199):672-83. doi: 10.1016/s01406736(19)31791-x.

27. Jafari F, Khatony A, Rahmani E. Prevalence of selfmedication among the elderly in Kermanshah-Iran. Glob J Health Sci. 2015;7(2):360-5. doi: 10.5539/gjhs.v7n2p360.

28. Silveira EA, Dalastra L, Pagotto V. Polypharmacy, chronic diseases and nutritional markers in community-dwelling older. Rev Bras Epidemiol. 2014;17(4):818-29. doi: 10.1590/1809-4503201400040002.

29. Kim HY, Kim JK, Shin GG, Han JA, Kim JW. Association between abdominal obesity and cardiovascular risk factors in adults with normal body mass index: based on the sixth Korea National Health and Nutrition Examination Survey. J Obes Metab Syndr. 2019;28(4):262-70. doi: 10.7570/ jomes.2019.28.4.262.

30. Yang S, Nguyen ND, Center JR, Eisman JA, Nguyen TV. Association between abdominal obesity and fracture risk: a prospective study. J Clin Endocrinol Metab. 2013;98(6):2478-83. doi: 10.1210/jc.2012-2958.

31. Nelson LA, Ackerman MT, Greevy RA Jr, Wallston KA, Mayberry LS. Beyond race disparities: accounting for socioeconomic status in diabetes self-care. Am J Prev Med. 2019;57(1):111-6. doi: 10.1016/j.amepre.2019.02.013.

32. Chen E, Martin AD, Matthews KA. Understanding health disparities: the role of race and socioeconomic status in children's health. Am J Public Health. 2006;96(4):702-8. doi: 10.2105/ajph.2004.048124.
33. Assari S, Bazargan M. Race/Ethnicity, socioeconomic status, and polypharmacy among older Americans. Pharmacy (Basel). 2019;7(2). doi: 10.3390/pharmacy7020041.

34. Volaklis KA, Thorand B, Peters A, Halle M, Heier M, Strasser B, et al. Physical activity, muscular strength, and polypharmacy among older multimorbid persons: results from the KORA-Age study. Scand J Med Sci Sports. 2018;28(2):604-12. doi: 10.1111/sms.12884.

35. American Diabetes Association. 5. Lifestyle management: standards of medical care in diabetes-2019. Diabetes Care. 2019;42(Suppl 1):S46-S60. doi: 10.2337/dc19-S005.

36. Nishimura R, Kato H, Kisanuki K, Oh A, Hiroi S, Onishi Y, et al. Treatment patterns, persistence and adherence rates in patients with type 2 diabetes mellitus in Japan: a claimsbased cohort study. BMJ Open. 2019;9(3):e025806. doi: 10.1136/bmjopen-2018-025806.

37. Rivas A, Vera Z, Marin GH, Lugo GB, Domenech MG, Samaniego L, et al. Factors associated with the lack of adherence to drug therapy in diabetic patients. Asclepius Med Res Rev. 2019;2(1):1-5.

38. Davari M, Bayazidi Y, Esteghamati A, Larijani B, Kebriaeezadeh A. The prescription pattern of anti-diabetic medication and glycemic control in type 2 diabetes in Iran; a patient-level study. Diabetes Manag. 2019;9(2):57-65.

39. Zarich SW. Treating the diabetic patient: appropriate care for glycemic control and cardiovascular disease risk factors. Rev Cardiovasc Med. 2003;4 Suppl 6:S19-28. 